\section{Literature Abstracts}

\section{Bansal V, Singh S, Garg N, Dubey P. Transport distraction osteogenesis as a method of reconstruction of the temporomandibular joint following gap arthroplasty for post-traumatic ankylosis in children: a clinical and radiological prospective assessment of outcome. Int J Oral Maxillofac Surg. 2013 Sep 6.} [Epub ahead of print] [Medline: 24016549] [doi: 10.1016/j.ijom.2013.07.745]

This clinical and radiographic stu

dy investigated the use of transport distraction osteogenesis in unilateral temporomandibular joint (TMJ) ankylosis patients.

Six patients aged between 4 and 8 years were selected for the study; the mean preoperative maximal interincisal opening (MIO) was $3.5 \mathrm{~mm}$ without lateral and protrusive mandibular movements. The ankylotic mass along with the posterior border of the ascending ramus was exposed via 'lazy-S' incision. A gap arthroplasty was performed, followed by a 'reverse L' osteotomy on the posterior border of the ramus. In-house manufactured extraoral distraction devices were used for this prospective study.

Follow-up clinical and radiographic evaluation was carried out for 13 - 27 months after completion of the activation period. After a mean follow-up of 19 months, the mean MIO was $29.1 \mathrm{~mm}$ and the lateral and protrusive movements changed from none to slight. Cone beam computed tomography images of all patients showed remodelled neocondyle created by transport distraction osteogenesis with no statistically significant differences observed for average cancellous bone density, trabecular number, and trabecular spacing between the neocondyle of the operated side (test) and the condyle of the non-operated side (control).

Authors concluded that neocondyle formation by transport distraction osteogenesis using the in-house distraction device is a promising treatment option for $\mathrm{TMJ}$ reconstruction in ankylosis patients.

Jones R. The use of virtual planning and navigation in the treatment of temporomandibular joint ankylosis. Aust Dent J. 2013 Sep;58(3):358-67. Epub 2013 Jul 31. [Medline: 23981219] [doi: 10.1111/adj.12086]

Temporomandibular joint ankylosis is not common in our community but can occur as a result of severe facial trauma or significant connective tissue disorders such as rheumatoid arthritis, osteoarthritis and psoriatic arthritis, and unfortunately as a result of iatrogenic causes. Ankylosis surgery is aimed at gap arthroplasty and mobilization of the joints.

However, the removal of the bony ankylosis and the production of a gap between the ramus of the mandible and the base of the skull is often difficult because of the size of the ankylosis and the anatomy on the inner aspect of the mandible. As a result of this, the author has found that surgical navigation has been useful with the removal of the ankylosis, both on the medial side of the mandible and the cranial base. Once the ankylosis has been freed and the mandible mobilized, the gap arthroplasty needs to be maintained or the release of the ankylosis will fail and the joints will re-ankylose. It is important to maintain the space produced by the arthroplasty but this is difficult when autogenous materials such as temporalis muscle, dermis fat and other like materials are used. The gap ultimately closes under the influence of the masseter and medial pterygoid muscles and the ankylosis may return.

This case report presents three representative patients in whom ankylosis has been released and the gap reconstructed with a total alloplastic joint replacement. All patients have had their ankylosis removed with the aid of a navigation system and all patients have been reconstructed with bilateral Biomet prosthesis. One patient has had their implant selected using virtual planning and the production of templates to help with placement of the stock implant.

Kodama Y, Tanaka R, Kurokawa A, Ohnuki H, Sultana S, Hayashi T, Iizuka T, Takagi R. Severe destruction of the temporomandibular joint with complete resorption of the condyle associated with synovitis, acne, pustulosis, hyperostosis, and osteitis syndrome. Oral Surg Oral Med Oral Pathol Oral Radiol. 2013 Aug;116(2):e128-33. Epub 2013 May 8. [Medline:23664782] [doi: 10.1016/j.00oo.2013.03.011]

The synovitis, acne, pustulosis, hyperostosis, and osteitis (SAPHO) syndrome consists of a combination of inflammatory bone disorders and dermatologic pathology. Bone lesions as a form of diffuse sclerosing osteomyelitis in the mandible occur in the posterior body and ramus. Bone lesions rarely spread to the temporomandibular joint (TMJ) where ankylosis may result. Herein authors present an unusual case of SAPHO syndrome with TMJ involvement in which severe destruction of the TMJ occurred. They observed an extension of the invasive soft tissue lesion into the infratemporal fossa from the TMJ with complete resorption of the condyle. In contrast to other previously reported cases, in present case the condyle was strongly suspected as the primary site of the bone lesion with subsequent extension to the ramus 
and infratemporal fossa.The destructive nature and related symptoms resembled a malignant tumour.

\section{A J S, E G. One-year prospective outcome analysis and complications following total replacement of the temporomandibular joint with the TMJ Concepts system. Br J Oral Maxillofac Surg. 2013 Oct;51(7):620-4. Epub 2013 Apr 22. [Medline: 23618995] [doi: 10.1016/j.bjoms.2013.03.012]}

Total replacement of the temporomandibular joint (TMJ) is increasingly accepted as the gold standard for reconstruction of irreparably damaged or ankylosed joints. The TMJ Concepts system (TMJ Concepts, Ventura, USA) has the longest follow-up of the 2 systems used in the UK.

A total of 74 patients had placement of TMJ Concepts prostheses. The primary diagnoses were degenerative disease, multiple previous operations, injury, rheumatoid arthritis, psoriatic arthritis, ankylosing spondylitis, and ankylosis. Of these, 12 were revisions of previous replacements ( 3 after multiple operations). Over the year there was a significant mean (SD) reduction in pain score $(10 \mathrm{~cm}$ visual analogue scale) from $72(2.5)$ to $8(1.7)(\mathrm{P}<0.0001)$, and mean (SD) improvements in mouth opening from $22.4 \mathrm{~mm}$ (9.4) to $33.7 \mathrm{~mm}(6.2)(\mathrm{P}<0.0001)$, and dietary consistency $(10 \mathrm{~cm}$ analogue liquid 0 to solid 100) from $38(23)$ to 93 (16) $(\mathrm{P}<0.0001)$. No patient had worse symptoms postoperatively. Joints in 2 patients failed because of biofilm infections. Two patients required blood transfusion and one required ligation of the external carotid artery. Five had perioperative dislocation, which responded to elastic intermaxillary fixation for one week. A total of 31 patients had partial, and 2 had total weakness of the facial nerve. All resolved fully except weakness of the temporal branch in one patient, which required brow lift.

Authors concluded that total TMJ replacement gives good early improvements in function and pain with few complications. Of the 74 patients, 71 were very pleased to have had the procedure. One was dissatisfied despite complete pain relief and improvement in mouth opening from 3 to $30 \mathrm{~mm}$, and 2 were ambivalent (one had infection, revision, and permanent weakness of the temporal branch of the facial nerve).

Babu L, Jain MK, Ramesh C, Vinayaka N. Is aggressive gap arthroplasty essential in the management of temporomandibular joint ankylosis?-a prospective clinical study of 15 cases. Br J Oral Maxillofac Surg. 2013 Sep;51(6):473-8. Epub 2012 Dec 5. [Medline: 23219020] [doi: 10.1016/j. bjoms.2012.11.004]

The purpose of this three-year, prospective, followup study was to evaluate whether aggressive gap arthroplasty is essential in the management of ankylosis of the temporomandibular joint (TMJ).

Fifteen patients were treated by the creation of a minimal gap of $5-8 \mathrm{~mm}$ and insertion of an interpositional gap arthroplasty using the temporalis fascia. Eleven patients had unilateral coronoidectomy and 4 bilateral coronoidectomy based on Kaban's protocol. Preoperative assessment included recording of history, clinical and radiological examinations, personal variables, the aetiology of the ankylosis, the side affected, and any other relevant findings. Patients were assessed postoperatively by a surgeon unaware of the treatment given for a minimum of 3 years, which included measurement of the maximal incisal opening, presence of facial nerve paralysis, recurrence, and any other relevant findings.

Of the 15 patients (17 joints), 12 had unilateral and three had bilateral involvement, with trauma being the most common cause. The patients were aged between 7 and 29 years (mean (SD) age 20 (8) years). Preoperative maximal incisal opening was $0-2 \mathrm{~mm}$ in 8 cases and $2-9 \mathrm{~mm}$ in 9 . Postoperatively adequate mouth opening of $30-40 \mathrm{~mm}$ was achieved in all cases, with no recurrence or relevant malocclusion during 3-year follow up. However, patients will be followed up for 10 years.

Aggressive gap arthroplasty is not essential in the management of ankylosis of the TMJ. Minimal gap interpositional arthroplasty with complete removal of the mediolateral ankylotic mass is a feasible and effective method of preventing recurrence.

Literature Abstracts.

J Oral Maxillofac Res 2013;4(3):a1

URL: http://www.ejomr.org/JOMR/archives/2013/3/a1/v4n3a1ht.pdf doi: $\underline{10.5037 / j o m r .2013 .43 a 1}$ 
Copyright $(C)$ Literature Abstracts. Published in the JOURNAL OF ORAL \& MAXILLOFACIAL RESEARCH (http://www. ejomr.org), 1 October 2013.

This is an open-access material, published in the JOURNAL OF ORAL \& MAXILLOFACIAL RESEARCH, distributed under the terms of the Creative Commons Attribution-Noncommercial-No Derivative Works 3.0 Unported License, which permits unrestricted non-commercial use, distribution, and reproduction in any medium, provided the original work and is properly cited. The copyright, license information and link to the original publication on (http://www.ejomr.org) must be included. 